\title{
Employee's Involvement Culture of Star Hotels in Pokhara
}

\author{
Daya Raj Dhakal, PhD*
}

\begin{abstract}
Since the star hotels are directly relates to the both internal and external tourism it has important contributory role to the nation therefore smooth operation of the hotels is most. Looking to current performance of the hotels some of the hotels are in loss condition and therefore it becomes challenging issues for both hotel management and Nepal government. Several numbers of literatures have explained an employee involvement practice is one that affects organizational performance. Therefore this study attempts to explore existing situation of employee involvement culture and its association with performance of star hotels in Pokhara. Since Nepal government announced Nepal Visit Year 2020 this study is highly relevant. This study compare between hotels having involvement practices and non-involvement practices in association with their financial performance in Pokhara. The advantage of this research is broadly defined into three sets of variables as employee empowerment, team work and carer development that focus interrelationship with star hotel's performance. The result revealed the hotels which have adopted employee involvement practices mostly get good financial result and vice versa. The result shows there is strong relationship between employee empowerment and team work practice with better financial result. Though previous literature explained career development is strong variable that supports performance, but in the Nepalese context this variable does not have significant impact. Hence, the study concludes that the management must give high priority to employee empowerment and team work and less priority to career development for better financial performance of the star hotels in Pokhara.
\end{abstract}

Keywords: Involvement culture, organization, performance, star hotels.

\section{INTRODUCTION}

Involvement of employees in decision-making process supports a strong sense of psychological commitment and ownership to their organization goals. Low-involvement culture is an obstacle to respond with fundamental environmental change associated with performance of the organization (Denison \& Mishra, 1995). Denison's theory stated that high levels of involvement and employee participation creates a sense of ownership and responsibility towards their individual and organizational objectives as well. High level of involvement culture in the organization is a consequence of increasing the quality decisions for the betterment of organization (Horman, 2013). Number of scholars and professionals give high emphasis to study about employee involvement culture and its impact to the organization. Employee involvement culture keeps organization strong that leads towards objectives and success (Bhatti \& Qureshi, 2007). Ogbonna (2000) have examined employee involvement culture and its association with performance of the enterprises. Denison and Mishra's (1995) theory focuses on four cultural traits involvement, consistency, adaptability, and mission as key determinants of business performance.

*Dr. Dhakal is Associate Professor in Pokhara University.Email: dayarajdhakal@gmail.com 
But in Nepalese context, researchers are not giving adequate attention towards the study of employee involvement culture and its association with performance. Among these, hotel business in Pokhara is one ignored area where researcher does not give adequate attention. Since hotel business is a core sector associates with tourism business and national economy, it must be given high emphasis to promote hotel business in Nepal (GoN report, 2015). Despites these importance, researcher are not giving importance to the study over employee involvement culture associates with hotel business in Pokhara. These evidences show that study of employee involvement culture in hotel business (star) is highly required. Realizing this real fact, the study tries to fill up this gap and explore status of employee involvement culture and performance of star hotel businesses in Pokhara. The fundamental aim of this research is to find how employee involvement culture affects the overall performance of star hotel business in Pokhara. Adhikari (2008) stated that main barriers prevailing in the employee relations system are over centralization of power, lack of trustful relations of top management with line management. This fact indicates the problems of employee participation in the Nepalese organization which is the major motivational factor of this study. Employee believe that nepotism and favouritism were widespread in the recruitment and selection process, decision making practice highly centralised even to deal with minor HR responsibilities, jobs are not so challenging for managers and the reward system not properly link with performance. In addition to this, Adhikari and Gautam (2009) stated that lack of formal performance appraisal and lesser use of performance based system create high level dissatisfaction at work place in the Nepali organizations. This fact also indicates the problem of employee involvement. Prior to 1990, human resource management practices were not satisfactory because of lack of poor state of employee participation (Agrawal, 2005). This is another issue addressed by the study. Major objective of this study is to examine the relationship between employee involvement culture and its association with performance of hotel businesses in Pokhara. And next objective associated with examining the present status of employee involvement adopted by star hotels operating in Pokhara.

\section{Research hypothesis}

Bhatti and Qureshi (2007) stated that there is a strong association between performance and employee involvement culture in the organization and justified those organizations can increase the performance that have employee involvement practices. They further stated that due to difference of employee involvement practices, the organization yield different result in the same industry and location. Thus, it is now assume that employee involvement culture has significant role for the betterment of performance. Hence, the first null hypothesis is set as:

$H_{0}:$ Employee involvement culture has no significant relationship with performance of star hotels in Pokhara.

Employee empowerment is strong organizational culture associated with organization's objectives. Empowerment of employees in decision-making process supports a strong sense of psychological commitment which consequently of increasing the productivity of an organization (Denison \& Mishra, 1995). Therefore, the second null hypothesis is set as:

$H_{0}$ : Employee empowerment cultural trait has no association with performance of star hotels in Pokhara. 
Team work culture in an organization shows better results, high employees' commitment, better productivity, career development, and other behaviours, that gives higher satisfaction and overall performance. Every organization should develop team work strategy that empower and increase the employee morale and job satisfaction to enhance high level productivity, which ultimately results customer satisfaction and retention (Sageer, Rafat \& Agarwal, 2012). All these evidences stated that organizations need to develop team work culture. Therefore, the third null hypothesis is set as:

\section{$H_{0}:$ Team work cultural trait has no association with performance of star hotels in Pokhara.}

The process of enabling employees to better understand and develop their career skills through training and coaching help to supports employee for decision making process and develop positive energy (Khan, Jam, Akbar, \& Hijazi, 2011). This evidence stated that organizations need to consider career of the employee and therefore forth null hypothesis is set as:

$H_{0}$ : Career development cultural trait has no association with the performance of star hotels in Pokhara.

\section{Theoretical Framework}

Theory explained empowerment, team work and career development have strong association with performance which are highlighted by the number of authors on their past study, this study too have similar approach of theoretical framework. The framework exhibited in Figure 1 shows the detail of theoretical frames used in this study.

\section{Independent variables}

\section{Dependent variable}

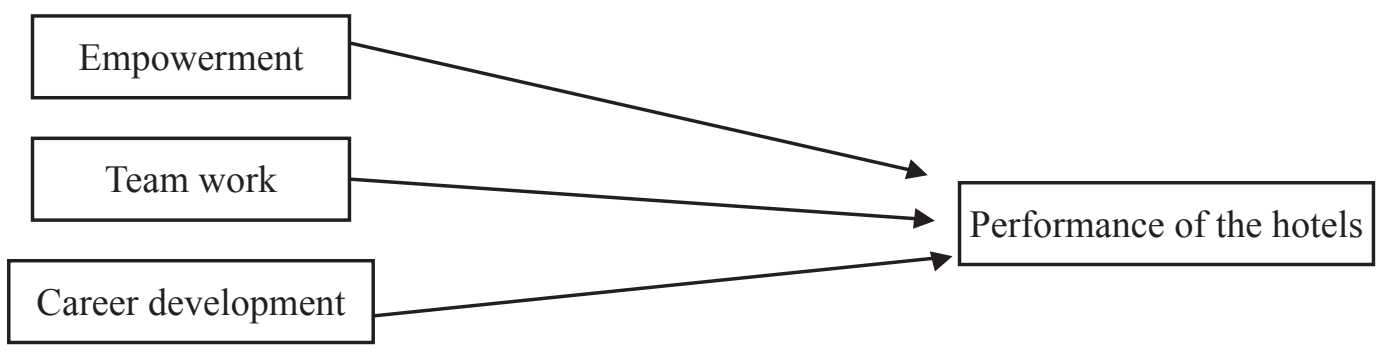

Figure 1. Theoretical framework.

The framework shows in Figure 1 explain employee empowerment, teamwork and career development of the employees have association with performance of the star hotels. The framework further explains higher the degree of employee empowerment, teamwork and career development positively associates with performance. For example, empowered employees performance in the organization is better than those who are not. Since empowerment, team work and career development affects financial performance, these variables consider as independent variables. This explained, the framework described performance of the hotels is depends to employee empowerment, teamwork and career development. Therefore, performance of the hotel is dependent variable. 


\section{LITERATURE REVIEW}

The employees' participation in management specifies an attempt of an employer to build employees into the team work towards the realization of a common goal. It is a mental and emotional involvement of a person that encourages to contribute on common goals and share responsibilities within members (Rotenberry \& Moberg, 2007). Therefore, employee involvement is the process of employee participation in the decision making process of the organization. It is democratic philosophy where employees are inspired to share their experiences and ideas for the betterment of the organization. Kim (2002) highlighted that employee involvement culture brings sense of belongingness, self-recognition, and acceptance of objectives for organizational effectiveness. In an employee in Employees are more committed with organization than those who don't have involvement culture (Khan, Jam, Akbar, \& Hijazi, 2011). Bhatti, Nawab and Akbar (2011) assertion that investment in employee involvement in an organization showed high employees' commitment, better productivity, and career development that gives higher level satisfaction and performance. Every organization should develop team work strategy that increase employee morale and job satisfaction to enhance high level productivity and performance (Sageer, Rafat, \& Agarwal, 2012). Therefore it is concluded that high degree of ownership within organizational members is the result of greater commitment to the organization. Involvement culture promote the ownership and that ownership develop a greater amount of input from the employees leading towards objective of the organization. Denison and Mishra (1995) stated that organizational culture model is based on four cultural traits involvement, consistency, adaptability, and mission that have strong association with performance. They further stated that high level of employee involvement is the result of sense of ownership to the employees in the organization. Therefore employee involvement in the organization promotes use of employees' inner potentiality that positively associates with increment of productivity.

Rashid (2013), opined manager's attitude and employee performance are highly correlated in the banking sector of Pakistan. He explained employee job satisfaction is strongly associated with leadership and motivation in Pakistan. Yasir (2011), explored the job satisfaction status in private bank of Pakistan and concluded that employees working in the private banks are highly satisfied which is major factor of overall bank's performance. He viewed that impact of HR practices like work autonomy, team work and leadership highly correlate with that job satisfaction. Diefendorff, Brown, Kamin and Lord (2002), opined that involvement on the job performance is correlate with behaviour of the citizen. They further stated that there is no significant difference between male employee performances with female's performance. Teams in the organization viewed as a primary components of modern management theory and practices (Tennant \& Langford, 2007).

\section{RESEARCH METHODOLOGY}

First of all, the study identified the stars hotels that are currently practicing involvement culture in their organization. The measurement of involvement culture is based on number of trainings offer to employee, employee participation in the meeting and internal promotion. The measurement of involvement culture is applied to all categorical hotel separately. Out of total employees if 25 percent or more are getting training opportunity and 10 percent or more are getting internal promotion for each year, it is considered as hotels with involvement culture. The measurement of weak culture are based on number of training offer to employees and employee participation in the decision making process. The measurement of weak involvement culture has applied to all categorical hotel separately. Out of total employees if less than 25 percent employee are getting training opportunity and less than 10 percent are 
getting internal promotion for each year, it is considered as hotels of non-involvement culture. This step confirmed and identified three clusters i. e. five star, hotel with involvement culture and non-involvement culture hotels. The hotels having involvement culture as explained above is considered as hotels with involvement culture and those who have not non-involvement culture hotels. The objective of this step is to separation of hotel based on their involvement practices and finds their association with performance.

After separation of hotels, a structured questionnaire has prepared for pilot testing. The measurement of performance is entirely based on financial performance i. e profit. Then after, questionnaire is distributed to the samples separately. The data collection process includes door-to-door visit to the hotels and collecting filled-up questionnaire. The collected data are arranged properly and put it into SPSS software. For measurement, the survey instrument on a five-point likert scale with anchors strongly agree $(=1)$ to strongly disagree $(=5)$ has been used. This framework focuses on cultural traits of empowerment, team work and career development associated with performance (Applicable to all three clusters). Before measurement, the cronbach alpha and factor analysis test have used using SPSS software. After confirmation of reliability, the data has analyzed using different statistical tools correlation analysis, chi square test, descriptive analysis, scattered diagram and regression analysis along with test of significance. After analysis and measurement of data, concluding remarks have been presented explaining the existing level involvement culture with the performance of the star hotels in Pokhara

The population of this study is total employee of star hotels working in FY 2075/76 i. e. 611. Only permanent employees are included in the population. Before determining the sample, total employees of all selected hotel add together and use the software for sample finalization. The total calculated sample is again distributed on proportional base and determine sample of each hotels. The hotels which do not have licence (although they claim star hotel) are excluded. After confirmation of sample, the study begins with identification of three clusters (five star, involvement/non-involvement culture) and judgemental sampling has used. Standard sample size calculator namely 'Best Survey Software' used for sample determination which is especially recommended for social research. It is most popular survey software used in likert scale questionnaire. Three hundred and thirty-four samples is confirmed size for further analysis.

The study conducted pilot test before the survey. Cronbach alpha was used to measure the internal consistency between set of items in the questionnaire. Principal component analysis (PCA) which is closely related to exploratory factor analysis (EFA) is used to identify the factors. This test was used to see whether the empowerment, team work and career development are supported by factor or not. Fiedel (2005) stated that less than 50 samples are inappropriate for sample adequacy test. Therefore, sample adequacy test has applied for further analysis.

\section{RESULTS AND DISCUSSION}

\subsection{Reliability and Validity}

Before analyzing the data, the reliability test have been carried out. The first result has suggested that some variables need to be removed before the analysis. The reliability and validity test continue until the Cronbach alpha gives reliable result. Further analysis has made when cronbach alpha result shows 0.62 , $0.59,0.59$ to five star case, non-involvement case and involvement case respectively. This consistency test is further verified with sample adequacy test. This test measures whether the data is sufficient to analyze or not. Kaiser suggested that KMO value 0.5 is barely acceptable, 0.7 to 0.8 is acceptable and more than 0.8 is extremely good for sample adequacy. Therefore, it is necessary to test sampling adequacy of all three categories and results are as follow. 
Table 1

Sample Adequacy Test

\begin{tabular}{clccc}
\hline S. N. & \multicolumn{1}{c}{ Clusters } & Sample size & KMO value & P value \\
\hline 1 & Five star case & 111 & 0.67 & 0.000 \\
2 & Non-involvement case & 167 & 0.75 & 0.000 \\
3 & Involvement case & 162 & 0.74 & 0.000 \\
\hline
\end{tabular}

The adequacy test shows that sample size is enough to run the factor analysis for all three cases. KMO test in all cases are $0.67,0.75$ and 0.74 respectively with sig value 0.000 ( $p>0.000)$. This result allow for analyzing the factor confirmation of all three cases. For this, correlation matrix and anti-image correlation matrix is used to find out any inconsistency between the variables. After that, the data analyze and run the correlation matrix and anti-image correlation to identify inconsistency if any.

\subsection{Cluster Wise Analysis of Performance}

In order to find the association between involvement and performance of the hotel, the collected data are analyzed through mean and SD. The basic purpose of this study is to find out variables effects on performance as respond by respondent. Each individual variable's mean and SD are calculated, tabulated and compared. After calculation of each individual variable mean and SD, the result has crossed and verified with statistical explanation and finds whether the result statistically proved or not. For that, one way ANOVA test has been applied and found the result. If sig value of AOVA is significant at 5 percent level, then it ensures results are statistically proved. After looking to mean and SD of all three clusters, the result shows five stars hotel and the hotel with involvement culture have similar in nature. The result exhibit there is no significant different between these two clusters regards to involvement practices. On the contrary, the hotels with noninvolvement culture have weak result and mean value more than 3 indicates the poor involvement culture in their organization. Like this, SD result also shows less than one result that indicates there is no significant difference between the responded. After analysis of mean and SD, the study concluded significant difference between hotels with involvement culture and non involvement culture regarding with performance. But question arises is that result statistically proved or not?. Therefore $t$ statistic has been used with following hypothesis set and analyzed.

There is no significant difference of mean and SD between three different cluster results in regards to involvement practices.

After that, following result is observed in group statistic.

Table 2

\section{Cluster Wise Group Statistics}

Group statistics

\begin{tabular}{lccc}
\hline Cluster & Mean value & \multicolumn{1}{c}{ sig value } & Remarks \\
\hline Five star cluster & 1.87 & 0.847 & Null rejected \\
Non involvement cluster & 3.14 & 0.023 & Alternative accepted \\
Involvement cluster & 1.97 & 0.855 & Null rejected \\
\hline
\end{tabular}


The result exhibits null hypothesis rejected to five stars and involvement cases. i.e there is no significant difference between five star hotels and hotels with involvement culture associated to performance. On the contrary, hotels of non-involvement culture accept the alternative hypothesis and justify poor involvement culture.

\subsection{Correlation Result with Performance}

The test explores correlation of three different clusters separately i. e. five stars cases with 111 samples, involvement cases with 146 sample and non-involvement case with 167 sample. After running the bivariate correlation, the following results obtained.

Table 3

Correlation of Non-Involvement Case

\begin{tabular}{lcrrr}
\hline \multicolumn{4}{c}{ Correlation of non-involvement case, $\mathrm{N}=167$} & \\
\hline Variables & Empowerment & Teamwork & Career dev & Performance \\
\hline Empowerment & 1 & 0.183 & 0.386 & 0.226 \\
& & 0.018 & 0 & 0.003 \\
Teamwork & & 0.22 & 0.016 \\
& & & 0.004 & 0.837 \\
Career dev & & 1 & 0.235 \\
& & & 0.002 \\
\hline
\end{tabular}

Table 3 shows that empowerment and career development cultural traits have significant association with performance. On the contrary, team work cultural trait has no such association. Career development and empowerment traits have similar level correlation with performance. Though there is association but the correlation value is less and no asterisk $\left(^{*}\right)$ indicated. This indicates weak association of these variables with performance. Since $\mathrm{p}$-value is less than $0.05(\mathrm{p}>0.05)$ for empowerment and career development at $5 \%$ level, the result is statistically proved. It is therefore concluded that career development and empowerment cultural traits have association with performance though correlation value is moderate. This correlation result is further verified with five star case.

Table 4

Correlation of Five Star Case

\begin{tabular}{lcrrr}
\hline \multicolumn{4}{c}{ Correlation of five stars case, $\mathrm{N}=111$} & \\
\hline Variables & Empowerment & Teamwork & Career dev & Performance \\
\hline Empowerment & 1 & 0.195 & 0.189 & 0.447 \\
& & 0.04 & 0.047 & 0 \\
Teamwork & & 0.324 & 0.309 \\
& & & 0.001 & 0.001 \\
Career dev & & & 0.136 \\
& & & 1 & 0.155 \\
\hline
\end{tabular}

This case represents involvement culture of five stars hotel and its association with performance. 
The result exhibits different result than non-involvement case above. The result revealed empowerment and teamwork have association with performance and no such association to career development with significant p-value at $5 \%$ level. Two variable's p-value is less than 0.05 at $5 \%$ level of significance except career development. Therefore, it is concluded that empowerment and team work involvement cultural traits have significant impact to performance of the hotels. This result again verified with involvement case and detail is as follow.

Table 5

Correlation of Involvement Case

\begin{tabular}{lcrrr}
\hline \multicolumn{5}{c}{ Correlation of involvement case, $\mathrm{N}=146$} \\
\hline Variables & Empowerment & Teamwork & Career dev & Performance \\
\hline \multirow{2}{*}{ Empowerment } & 1 & -0.048 & 0.186 & 0.161 \\
& & 0.561 & 0.025 & 0.052 \\
Teamwork & & 0.324 & 0.257 \\
& & & 0 & 0.002 \\
Career dev & & & 1 & 0.016 \\
& & & & 0.852 \\
\hline
\end{tabular}

This matrix case represents all the hotel which have good involvement practices. The result exhibits almost similar result with five stars case above and justify teamwork and empowerment has strong association with performance and poor association of career development. The p-value of empowerment and team work has less than 0.05 at $5 \%$ level of significance. Most cases, correlation is significant at $99 \%$ level of confidence. Observing to three different cases separately, it is almost same result between five stars case and hotels having involvement practices. Just opposite, hotels of non-involvement practices have different result and exhibited team work have no association with performance. Therefore result concludes hotels having good employee involvement practices exhibits good team work and employee empowerment culture.

In order to justify computed correlation value above, the following hypothesis are set and tested.

$H_{0}:$ The observed correlation result is not real and it is chance of occurrence.

$H_{1}$ : The observed correlation result is real and it is not chance of occurrence.

The result is tested with p-value and observe whether p-value lesser than 0.05 or not. If the result is less than 0.05 then it is significant i. e. null hypothesis rejected. Looking to the correlation result and p-value of empowerment and teamwork variables, it is significant at 5\% level. This proved that null hypothesis rejected and correlation result statistically proved.

\subsection{Chi Square Test}

This test has been used to determine whether employee empowerment, team work and career development traits associates with performance of hotels or not. Otherwise it would declare no association between these variables and financial performance. The test has applied to all three cases separately for the confirmation of association. For that, following null hypothesis is set and tested the result. 
H0: Empowerment, team work and career development has no association with performance of hotels in Pokhara.

After setting the hypothesis, the Pearson chi-square test is running using SPSS software and found the result of all three cases.

Table 6

Chi Square Test Result

Chi square test

\begin{tabular}{lcccccc}
\hline Test between variables & \multicolumn{2}{c}{ Five star case } & \multicolumn{2}{c}{ Involvement case } & \multicolumn{2}{c}{ Non-involvement case } \\
\cline { 2 - 7 } & $\chi 2$ & p-value & $\chi 2$ & p-value & $\chi 2$ & p-value \\
\hline Empowerment-performance & 397 & 0.000 & 201 & 0.000 & 142 & 0.000 \\
Team work -performance & 256 & 0.000 & 102 & 0.000 & 124 & 0.083 \\
Career dev -performance & 368 & 0.000 & 126 & 0.01 & 74 & 0.07 \\
\hline
\end{tabular}

Table 6 clearly explains that there is association of empowerment and teamwork with performance of five stars hotel and hotels having involvement culture. Similar to correlation result above, these two variables has strong association with performance. Therefore these two cases also gave similar result and proved association of performance with employee empowerment and team work involvement culture. This result exhibits career development have weak association. In the case of employee empowerment and team work, the p-value is less than 0.05 at 5\% level. The revealed results are statistically proved and reject the null hypothesis 'empowerment and team work has no association with performance of hotels in Pokhara. However, in case of career development, p-value is more than 0.05 and thus, accept the null hypothesis that 'career development has no association with performance of hotels in Pokhara. These evidences concluded that employee empowerment and team work involvement traits are associates with performance of five stars hotel and hotel having involvement practices and just opposite no such association of career development appears to the non-involvement culture hotels.

\subsection{Scattered Diagram}

If the variables are highly correlated, the scatter points fall on line or curve. The diagram explains the strength of relationship between the variables. If scatter dots of $\mathrm{x}$ and $\mathrm{y}$ increases simultaneously then it is positive correlation and linear relationship. The under mentioned table shows scattered diagram test of all three cases separately.

Table 7

Cluster Wise $R^{2}$ Linear Value

Scatter diagram test

\begin{tabular}{lccc}
\hline Test between variables & Five star case & Involvement case & Non-involvement case \\
\hline & $\mathrm{R}^{2}$ linear value & $\mathrm{R}^{2}$ linear value & $\mathrm{R}^{2}$ linear value \\
\cline { 2 - 4 } Empowerment-performance & 0.33 & 0.28 & 0.11 \\
Team work -performance & 0.39 & 0.29 & 0.03 \\
Career dev -performance & 0.21 & 0.19 & 0.05 \\
\hline
\end{tabular}


Table 7 exhibits $\mathrm{R}^{2}$ linear value of both five star and involvement cultural hotels categories which is relatively higher than non-involvement cases. Among them, team work variable is more strong. This indicates team work affects positively to the performance. Like this the empower too have significant with performance. This evidence proved that both employee empowerment and team work are necessary for the success of star hotels. The $\mathrm{R}^{2}$ linear value shows that the hotel having involvement culture gives more priority on employee empowerment and team work less priority to career development in their organization. On the contrary, the non-involvement case exhibits weak association of all three variables to the performance. These evidences also justified employee empowerment and team work culture are major variables influence to the performance and conclude that lack of employee empowerment and team work culture, hotels are suffering from loss.

\subsection{Employee Empowerment, Team Work, Career Development and Performance}

VIF test for multi collinearity: Multi collinearity problem shows the predictors are overlap in beta coefficient result while fitting regression. If multi collinearity problem appears in the regression then estimated beta coefficient vary, which is very sensitive to minor changes. For that, tolerance and Variance Inflation Factor (VIF) two collinearity diagnostic factors are used to identify multi collinearity. The VIF is 1 divide by tolerance. It is always greater than or equal to 1 and not exceeded 10. If the values of VIF exceed 10 then considered as multi collinearity. Similarly, tolerance is 1 minus R2 value and must be less than 1 . If the tolerance value exceeds 1 then it is considered as multi collinearity. The detail of VIF and tolerance is as follow.

Table 8

VIF Test For Multi Collinearity

\begin{tabular}{lllllll}
\hline \multirow{2}{*}{ Variables } & \multicolumn{3}{c}{ Five star case, } & \multicolumn{2}{c}{$\begin{array}{c}\text { Involvement case, } \\
\mathrm{N}=146\end{array}$} & \multicolumn{2}{c}{$\begin{array}{c}\text { Non-involvement case, } \\
\mathrm{N}=167\end{array}$} \\
\cline { 2 - 7 } & Tolerance & VIF & Tolerance & VIF & Tolerance & VIF \\
\hline Empowerment & 0.944 & 1.05 & 0.952 & 1.05 & 0.841 & 1.18 \\
Team work & 0.876 & 1.14 & 0.883 & 1.13 & 0.940 & 1.06 \\
Career development & 0.878 & 1.13 & 0.854 & 1.17 & 0.828 & 1.20 \\
\hline
\end{tabular}

The result of VIF and tolerance test shows that there is no problem of multicollinearity. The VIF and tolerance values are within. So, this result proved no multicollenarity problem between independent variables. After confirmation of no multicollinarity regression model is applied. Higher the beta coefficient of variable shows higher level of influencing and vice versa. The following results are obtained. 
Table 9

Regression of Categorical Sample Case

Hotel wise sample case

\begin{tabular}{lccc}
\hline \multicolumn{1}{c}{ Variables } & $\begin{array}{c}\text { Five star case, } \\
\mathrm{N}=111\end{array}$ & $\begin{array}{c}\text { Hotels with involvement } \\
\text { case, } \mathrm{N}=146\end{array}$ & $\begin{array}{c}\text { Hotels with non-involvement, } \\
\mathrm{N}=167\end{array}$ \\
\hline Constant $\alpha$ & 0.541 & 0.665 & 2.17 \\
Empowerment $\beta 1$ & 0.439 & 0.317 & 0.207 \\
p-value & 0.000 & 0.01 & 0.000 \\
Team work $\beta 2$ & 0.351 & 0.492 & 0.036 \\
p-value & 0.01 & 0.000 & 0.482 \\
Career development $\beta 3$ & 0.01 & 0.163 & 0.219 \\
p-value & 0.852 & 0.163 & 0.02 \\
R square & $52 \%$ & $59 \%$ & $67 \%$ \\
\hline Model fit p-value & 0.000 & 0.000 & 0.000 \\
\hline
\end{tabular}

The regression equation is shown as: $Y=\alpha+\beta_{1} X_{1}+\beta_{2} X_{2}+\beta_{3} X_{3}+\ldots \ldots \ldots .+$ error

Where

$\mathrm{Y}=$ Performance

$\alpha=$ Constant

$\mathrm{X}_{1}=$ Employee empowerment

$\mathrm{X}_{2}=$ Team work

$\mathrm{X}_{3}=$ Career development

The regression result of all three cases shows almost similar trend with above result and stated that employee empowerment and team work have significant association with performance. The result exhibits in case of non-involvement, $\mathrm{P}$ value is more than 0.05 at $5 \%$ level and justify weak association to performance which is opposite result with five star and involvement case. This is also justify with beta coefficient value appears in the regression table. But looking to five star and involvement case, the team work and employee empowerment traits have significant association with performance. In aggregate, one common result has drawn from all three cases and justifies no association of career development trait with performance of star hotels. Now, it is clear that star hotels are not getting high profit due to lack of employee involvement practices. Relatively employee empowerment trait has significant association to the performance. Since F value, model fit p-value and R square value justified the regression result, it is concluded that employee empowerment and team work are highly influencing factor with performance of stars hotel. The detail of each case regression result with beta coefficient is discussed below.

Five star case

$$
\begin{array}{rrr}
\mathrm{Y}=0.541+0.439 \mathrm{X}_{1}+ & 0.351 \mathrm{X}_{2}+ & 0.01 \mathrm{X}_{3} \\
(0.000) & (0.01) & (0.852)
\end{array}
$$


Theis regression equation explains career development is weak variable associates to performance and just opposite, employee empowerment and team work variables are highly influencing. Beta coefficient of employee empowerment and team work shows significant with p-value at $5 \%$ level. This concluded employee empowerment and team work cultures have strong association with performance. On the other hand, p-value of career development shows no association with performance with $(\mathrm{P}>0.05)$ at $5 \%$ level. The beta coefficient of employee empowerment and team work traits have $44 \%$ and $35 \%$ respectively.

\section{Involvement case}

$$
\begin{gathered}
\mathrm{Y}=0.665 \\
(0.01)
\end{gathered} \underset{(0.000)}{0.317 \mathrm{X}_{1}}+\underset{(0.163)}{0.492 \mathrm{X}_{2}}+0.163 \mathrm{X}_{3}+\ldots \ldots . .+ \text { error }
$$

This result explains similar result with five star case and shows employee empowerment and team work cultures have significant association with performance and no such association with career development. $\mathrm{P}$ value of career development is insignificant at $5 \%$ level $(\mathrm{P}<0.05)$ and highly significant to employee empowerment and team work result $(\mathrm{P}>0.05)$. The beta coefficient of employee empowerment and team work traits have $32 \%$ and $49 \%$ respectively. Relatively team work culture is highly significant variable associates with performance.

\section{Non-involvement case}

$$
\begin{aligned}
& \mathrm{Y}=0.810+0.207 \mathrm{X}_{1}+0.036 \mathrm{X}_{2}+0.219 \mathrm{X}_{3}+\ldots \ldots . .+ \text { error } \\
& \begin{array}{lll}
(0.000) & (0.482) \quad(0.02)
\end{array}
\end{aligned}
$$

This represents all star hotels having no involvement practices and explain the influencing degree of each independent variable associates to the performance. This regression result exhibits different result than other above two cases. This case explain team work practice has no association with performance $(\mathrm{p}<0.05)$ and just opposite employee empowerment and careers development have significant result at $5 \%$ level. Though employee empowerment and career development cases have significant result but their beta coefficient value relatively lesser than above two regression cases. Therefore, this result concluded hotels of weak involvement culture shows poor team work practices in their organization. The result is dissimilar to result of five star case and involvement case.

Overall regression result clearly exhibited that employee empowerment and team work involvement practices have significant association and weak association of career development to the performance of star hotels in Pokhara. Relatively team work involvement culture is significant variable associates with performance.

\section{Test of hypothesis}

All statistical result are almost consistent and justify employee empowerment and team work cultures are associate with performance. Just opposite, non- involvement case exhibits employee empowerment and team work cultures are insignificant variables associate with performance. In sum, the result disagree with null hypothesis and justify the following hypothesis set before

$H_{1}$ : Employee involvement culture has positive relationship with performance of hotels in Pokhara. 
The result explains that career development is weak variable that associates with hotel's performance. The evidences from statistical result revealed career development is a trait that poorly correlates with performance of the star hotel and justify the following null hypothesis set before.

$H_{0}$ : career development cultural trait has no association with the performance of star hotels in Pokhara.

The result explains team work culture is strong variable associate with performance. All statistical analysis used in the test explained the consistent result and shows strong association of team work with performance and disagree with null hypothesis and justify the following hypothesis set before.

$H_{1}:$ Team work culture that positively relates with performance of star hotels in Pokhara.

All statistical analysis used in the test explain employee empowerment is significant variable associates to the performance. All the evidence from statistical analysis revealed employee empowerment is strong variable associate with performance of hotels and disagree with null hypothesis and justify the following hypothesis set before.

$H_{1}$ : Employee empowerment culture that associates positively with employee performance of star hotel in Pokhara.

\section{MAJOR FINDINGS}

The study exhibits that team work and employee empowerment involvement practices are significant variables and highly associated with performance of the star hotel in Pokhara. This shows hotels having involvement culture empower to their employees and feel psychological ownership in their organization. The result is consistent with (Denison \& Mishra, 1995) findings and confirmed that employee involvement culture is highly influencing variable for the star hotels in Pokhara.

Team work is another variable that associates strongly with hotels profit. The result exhibits high performer hotels have good involvement culture around teams and share the employee's views each other. The result shows high-level correlation between profit of the star hotels and team work. Like employee empowerment, this variable too has significant influence to the profit of the star hotels. This explores combined effort of the employees makes the hotel more competitive.

The results also exhibits some dissimilarities compare with previous findings such as (Khan, Rehman \& Akram, 2012), (Rotenberry \& Moberg, 2007), (Tennant \& Langford, 2006) who explained career development is significant variable for performance. Unlike those findings, this result indicates career development is weak variable. The evidence shows, the hotels of non- involvement culture yield opposite relation with hotels having involvement culture.

Literature stated that employee empowerment and team work traits have been found to be universal influencing variable associates with performance. This study too produced similar result in the context of Pokhara and justified employee empowerment and team work cultures have strong association with performance. Therefore, it is confirmed that star hotels need to give high emphasis to empower to their employees, build up teamwork for better financial result. The hotels need to create such environment that develop employees more committed to their work and feel psychological ownership. 


\section{CONCLUSIONS}

Employee empowerment and team work cultures have significant association with performance of the stars hotel in Pokhara and justify that they are significant. Prior researches like (Denison \& Mishra, 1995), Rashid (2011), and (Rotenberry \& Moberg, 2007) also illustrated that employee empowerment and team work cultures have positive association for the success of the organisation and therefore the first conclusion of this study is - employee empowerment and team work cultures are universally accepted variables that strongly associates with performance of the organization.

Non-involvement practicing hotels do not give adequate attention to the employee empowerment and team work. On the other hand, the hotels having good involvement practices show good teamwork, employee participation culture in their organizational system. Since literatures explained employee empowerment and team work are vital variables, the second conclusion of this study is due to lack of employee empowerment and team work, non-involvement practicing stars hotels fail to achieve better financial result.

Apart from the overall analysis, it is proved that not all variables are equally important for the star hotels in Pokhara. The result exhibits different traits have different level of effects on the performance. In the case of Pokhara, they should give high emphasis to the employee empowerment and team work and minimal focus to career development. Therefore, the third conclusion of this study is star hotels in Pokhara should accord high emphasis to employee empowerment and team work.

Star hotels currently in operation level in Pokhara can highly benefit from the consequences of this indepth study. Since the result claims that hotels must give high emphasis to employee empowerment and team work, it is recommended that the hotel management team use this information while formulating future steps and strategies. The result provides adequate information to the hotel management team for guidelines and necessary ideas. The study recommends manager to give high priority to extend high attention on employee participation and should make conducive policy that supports to build up teamwork culture in the hotels.

\section{REFERENCES}

Adhikari, D. R. (2008). Human resource management. Kathmandu: Buddha Publication.

Adhikari, D. R. (2010). Human resource development for performance management. International Journal of Productivity and performance Management, 49(4), 306-324.

Adhikari, D. R., \& Gautam, D. (2009). Improving quality of work life through labour legislation. International Labour Organization (ILO), Decent Work Life.

Agrawal, G.R. (2005). Organizational relation in Nepal. Kathmandu: M.K. Publisher and Distributer.

Bhatti, K. K., Nawab, D. S., \& Akbar, D. A. (2011). Effect of direct participation on organizational commitment. International Journal of Business and Social Science, 2(9), 15-23.

Bhatti, K.K., \& Qureshi, T. M. (2007). Impact of employee participation on Job satisfaction, employee commitment and employee productivity. International Review of Business Research, 2, $54-68$.

Denison, D. R., \& Mishra, A. K. (1995). Toward a theory of organizational culture and effectiveness. Organization Science, 6(2), 204-223.

Diefendorff, J., Brown, D., Kamin, A., \& Lord, B. (2002). Examining the roles of job involvement and work centrality in predicting organizational citizenship behaviours and job performance. Journal of Organizational Behaviour, 23, 93- 108.

Fiedel, S. (2005). On custer's sins. North American Archaeologist, 26(1), 83-85.

Hassan, Y. (2007). Job satisfaction in private banking sector of Pakistan. Global Journal of Management and 
Business Research, 11(12), 84-93.

Horman, B. (2013). An investigation into job satisfaction and organizational commitment of construction personnel. Global Advanced Research Journal of Social Science, 2(1), 1-11.

Khan, D. M., Rehman, Z., \&Akram, M. W. (2012). The impact of employee commitment on employee satisfaction role of employee performance as a moderating variable. Singaporean Journal of Business Economics, and Management Studies, 1(2), 85-167.

Khan, T. I., Jam, F. A., Akbar, A., Khan, M. B., \& Hijazi, S. T. (2011). Job involvement as predictor of employee commitment. International Journal of Business and Management, 6(4), 252-262.

Kim, S. (2002). Participative management and job satisfaction: Lesson for management leadership. Public Administrative Review, 62(2), 231-241.

Ogbonna, E. (2000). Leadership style, organizational culture and performance: Empirical evidence from UK. International Journal of Human Resources Management, 11(4), 766-788.

Oparanma, A. O. (2010). The organizational culture and corporate performance. International Journal of African Studies, 3, 34-40

Rashid, S. (2011). Factor affecting the performance of the employees at work place in the banking sector of Pakistan. Middle-East Journal of Scientific Research, 17(9), 1200-1208.

Rotenberry, P. F., \& Moberg, P. J. (2007). Assessing the impact of job involvement on performance. Management Research News, 30(3), 203-215.

Sageer, A., Rafat, D. S., \& Agarwal, M. P. (2012). Identification of variables affecting employee satisfaction and their impact on the organization. Journal of Business and Management, 5(1), 32-39.

Tennant, S., \& Langford, D. (2006). Team performance measurement: Let's reward teamwork. $22^{\text {nd }}$ Annual ARCOM Conference, pp.189-197. 